\title{
Assessing International Students' Growth in U.S. Higher Education: ESL students in Focus
}

\author{
Aytaged Sisay Zeleke \\ Language and Culture Department, Delaware Technical Community College, U.S. \\ azeleke@dtcc.edu, aytagedz@gmail.com
}

\begin{abstract}
Students enroll in educational institutions, especially in ESL programs, to add as many values as possible their stay in an institution provides them.Accordingly, educational programs should meet these expectations, and they are also accountable for ensuring the different aspects of their programs are continuously improving based on program evaluation data.Unfortunately, most educational institutions are limited to using conventional courses achievement evaluation instruments, such as quizzes, tests, and final exams. Even though these measurement tools are necessary and vital, they are insufficient to assess students' holistic growth because of students' multifaceted involvement in an international higher educational institution. Therefore, this article using a possible ESL program in U.S.as an example proposes the need to integrate direct, indirect, and value-added assessments in educational programs when international students are assessed.
\end{abstract}

Keywords: Value Added Assessment, Direct, Indirect and Applied Value-Added Assessment,

DOI: $10.7176 /$ JLLL/81-04

Publication date:August $31^{\text {st }} 2021$

\section{Introduction}

According to the data compiled by the open door, 94,562 international students were enrolled in U.S. community colleges in 2018. (NAFSA, web). The United States of America is one of the most attractive countries for many international students for different reasons. A longitudinal study conducted by the International Education Institute ( IIE) has analyzed a total of 15,902 valid student responses for its study entitled "What International Students Think about U.S. Higher Education." ( IIE, 2015). In this study, prospective international students from five continents were surveyed to prioritize their preferred higher education learning destination countries. The countries presented to the students to choose from included: U.S., U.K, France, Germany, China, Australia, Canada, and Japan. The study found that $74.2 \%$ of the respondents indicated that the U.S. had been their most preferred destination country to study. Asked about their reasons for their preferences, the subjects of the study indicated a wide range of schools and programs ( $78.3 \%)$, high quality higher education system $(77 \%)$, welcoming international students $(67.7 \%)$, many scholarship opportunities ( $59.4 \%)$, good student support services $(56.8 \%)$, and safe place to study $(45.6 \%)$ as the primary reasons that attract them to study in the U.S).

As a condition to begin their major academic studies in U.S. higher education institutions, non -native English language speaking students have to demonstrate their English proficiency in various ways. Students' English language proficiency scores in standardized tests such as TOEFL, IELTS, SAT, and ACT, among others, are the most commonly accepted language proficiency measures. Based on students' scores in any one of these English language competency tests, college admission officers determine whether nonnative English language users should directly start their academic studies, or they should be given conditional admission until they satisfy the language proficiency requirement (See U.S.universities' websites for detailed and specific requirements on English language proficiency). Additionally, students whose native language is other than English could be admitted to community colleges without taking the above-standardized tests provided that they agree to take and pass ESL courses offered in their respective colleges before they begin their preferred fields of study ( see U.S. Community Colleges websites for details).

Admitted international students expect to grow in skills and knowledge when deciding to join higher education institutions abroad. Their growth needs as international students encompass more that academics. Thus, higher institutions should aim at adding values to international students and transition them from where they were in skills, knowledge, and experience to increased skills, knowledge, and experience levels. This clearly means that these institutions should meet students' expectations; questions to ask if the expectations are met include: to what extent have the institutions/instructors added values to students and how well the colleges/instructors helped students add new values? The issue, however, is that students' growth in higher education is not usually assessed holistically and reliably.

1.1.Purpose of ESL Courses: Higher education institutions in the U.S. offer different English language skills courses at beginner, intermediate and advanced levels for international and immigrant students. Moreover, most of the institutions teach English for Academic Purpose (EAP) courses. The courses in the beginning and intermediate levels usually aim to help students develop the English language competencies needed to function 
effectively for social and job-related purposes. The advanced level courses aim to develop the necessary academic language skills students need for social communication purposes and effectively navigate their academic studies in English. After completing the advanced level courses, those English as a Second Language (ESL) students whose goal is to pursue college-level education might take EAP courses.

1.2.The Why of Assessment in College: Students' learning assessment is conducted to gather data to monitor progress if students have understood course contents covered in a given period, and to measure if they have achieved course goals. In short, the primary purposes of these assessments are to diagnose students' progress (i.e., formative) and to determine their academic achievement (i.e., summative). (Hattie \& Timperley, 2007; Bachman \& Palmer, 2010).However,it should be noted that these assessment instruments do not capture students' holistic growth except measuring the improvement shown in and achievement of course objectives. For instance, international students' development in U.S.higher education institutions is not limited to language skills and academic courses they take in ESL classrooms. It also includes growth in knowing self, cultural and social skills, and personality. Learning and growth could come from a variety of sources while international students are in a foreign educational institution.

1.3.The Gap in Assessment and Proposal: My observation shows that higher education institutions evaluate students' achievement during and after every course. Nonetheless, it is not common to observe higher education institutions having a formal system that evaluates the holistic value - international students have added because of their being students in a given institution foreign to them. This paper, therefore, proposes integrating valueadded assessment with the existing assessment instruments to measure the multidimensional impact of attending a higher education institution as international students by utilizing the ESL program as an example.

Value-added assessment measures the values an educational institution has added to its students because of attending that institution. As many scholars agree, value-added assessment can provide diagnostic feedback to students and faculty members within single courses and programs and catalyze improvement efforts (Nunley, Bers and Hersh, 2011; Benjamin 2007). Specifically, it helps answer questions such as what difference does the [program]/institution make for its students? Is it more effective in making a difference now than in the past? Is it more effective than other similar institutions [programs] after controlling its incoming students' admissions scores and other relevant attributes? (Benjamin 2002:1)

Following the fundamental questions,Benjamin(2002:1) raised,it is cogent if I conceptualize value-added as the difference a particular college/ ESL program makes in the international students' English language skills, study skills, and American culture learning and values added in comparison to what these students have already had in these areas. Thus, I contend that the ESL students' growth can be maximized when the ESL program adds direct, indirect, and applied values. Values added measurement should be done by comparing data that show students' abilities before international students enter into the ESL program and assessing the students again during and after the students have gotten all the multidimensional learning experiences gained from ESL program in particular and their higher educational institution in general.

This paper proposes possible ways to measure the impact of an educational program (taking ESL as an illustration) on students' growth, focusing on three types of values students could add because of studying in an educational institution.

\section{Value Added Assessment}

Below are the proposed assessment approaches for consideration to assess international students in U.S. higher education institutions so that institutions and instructors can evaluate themselves to understand the extent to which they have added values to students. The application examples are focused on ESL program and its students; however, the approaches could be tailored to fit the nature of other programs.

\subsection{Direct Value-Added Assessment}

Direct value-added assessment measures what students know and can do when they start their ESL program. Then it compares the results with what they have achieved at the end of their ESL program in their college. Here, the entire program's effect on students' learning is evaluated (Nunley et al., 2011). For example, in many higher education institutions in the U.S., ESL students are placed in different levels and courses based on their placement test scores.However,students' placement data are not commonly used to compare against the knowledge and skills students gained after completing the program. If there were a culture of exhaustively using available data, institutions would be in a good position to measure the true impact of their program's curriculum and instruction on international students' success. In addition, experience has informed us that ESL students have different language proficiency levels, educational backgrounds, work, and life experiences; thus, their background is a factor to determine what values are added and not. One cannot simply assume students have necessarily added values without comparing pre and post data. 
Additionally, ESL programs and the institutions that house ESL programs add varying values; for some students, the values may be insignificant. For others, it could be incredibly significant. Thus, measuring and celebrating the program's and instructors' achievement in bringing students' learning growth based on only the end of a course or program evaluation result could be deceiving when the reference is students' holistic growth.

Taking this idea into a course level, ESL program administrators or instructors could introduce a pre-and post-course assessment to learn about the value each course has added instead of only measuring students' course progress after covering specific course objectives in the middle of a semester and students' achievement at the end of a course. Nevertheless, we must be cautious about the qualities (reliability, validity, item difficulty level, and discrimination power) of the pre and post-tests (Bachman 2000; Hughes 2003; \& Weir 2005).

ESL program administrators and instructors could use the assessment data to compare the program's courses and embark on intervention plans. Other stakeholders could also use the data for decision-making, policy development, and institutional improvement. However,one of the major limitations of this assessment is that other factors that may not necessarily be related to formal teaching, learning, and institutional factors may affect the post-assessment data outcome. For example, students' performance in the post-test may significantly improve. Thus, instructors or course administrators could be tempted to firmly conclude that the significant learning growth results from the instruction after the student(s) attended the ESL program in that institution. Nonetheless, the conclusion could be wrong since the improvement might be because the student(s) got extra help outside the school or may even be due to the quality of the measurement instrument used. Here, I am trying to note that interpretation of assessment data should be made cautiously to reach a sound conclusion and generalizations.

\subsection{Indirect Value-Added Assessment}

As its name tells, indirect value-added assessment indirectly assesses students' behaviors observed and activities done in an institution believed to correlate with their learning and success. Since the ESL program is the first destination for many international students when they join higher education institutions in the U.S.,ESL program administrators and instructors are expected to help develop students' English language skills and support their integration with the American culture and system.

One way to help these students integrate with American culture and values is to exploit the available resources to achieve this goal actively. For instance, colleges in the U.S. organize extra-curriculum activities such as debate, sport, culture, art, and writing clubs. Even though international students have many opportunities to engage with outside classroom activities and interact with American students, most students prefer to confine themselves within the ESL program-related activities and ESL people. It should be the program administrators and instructors' responsibility to facilitate international outside ESL class engagement.

The degree to which ESL departments and international students' offices are invested enough to integrate extra curriculum and American students into the ESL program and classroom might have a positive or negative impact in providing indirect values to students. For instance, if the integration of the ESL students in an institution is non-existent, it could leave international students isolated and behind other ESL students who can integrate. Experience shows that most ESL departments that organize educational tours do not usually include non- ESL students' participants. However, research suggests ESL students' active involvement in extra curriculum activities and interaction with native speakers correlate with ESL students' language, cultural awareness, and social skill development. For instance, ESL instructors may facilitate ESL students' language acquisition by actively engaging them in the college's extracurricular activities, making them interact with native speakers and American culture and values.

To assess the indirectly added value, college administrators could gather valuable information about the ESL students' ESL departmental support and identify weaknesses and strengths. The ESL department's and its instructors' role here is to establish a link between the courses offered and the college-wide activities, which could be considered as another model to the learning community practices, most colleges have. Even though it is difficult to estimate the actual students' learning in this model, the ESL departments' and instructors' facilitation roles could be appraised to improve the efforts made in adding indirect value to students' sociolinguistic skills growth.

\subsection{Applied Value-Added Assessment}

One of the ESL program's primary objectives is to help non-English-speaking students develop their English language and study skills to pursue their supportive and mainstream courses effectively. Thus, it is essential to measure the value the ESL program added to their accuracy and fluency in using the English language when studying their supportive and major courses after being awarded their ESL certificates. Examples of data collection instruments include interviews with alumni about how their ESL program prepared them to study their mainstream courses and interview their mainstream instructors to know whether former ESL students procure the necessary English language skills. In addition, international students receiving stakeholders, such as employers if the purpose of the students' ESL learning is job-related, could be interviewed or surveyed to elicit 
information that helps to identify gaps between what the ESL program prepares students for and employers' needs and expectations.

Applied value-added assessment data help to measure and learn about the outcome of a program. It has an important implication on the quality of the curriculum, methods of teaching, and assessment. However, it is difficult to precisely identify the program's impact on students since several intervening factors may exist between the time the students graduate from their ESL program and the time the value-added assessment is conducted.

\section{Final Remark}

Many higher education institutions usually determine students' success solely based on students' scores in tests, assignments, and final exams. Although this approach is common and valuable, it is not sufficient to capture reliably students' holistic growth, which results from a whole range of influencing factors students might have had in their learning and experiences while they are in college. Learners' growth is realized at different times and rates. This growth, especially for international students, should come from various learning opportunities created by their host higher education institution. The impact of their learning experiences determines the worth of international students' time and money investments, their growth holistically, and their readiness to navigate their academic, economic, and societal needs in their new country. Thus, introducing value-added assessment as an additional quality enhancement tool in higher education focusing on ESL programs is vital.

As international students' educators, we should use a measurement approach to evaluate how well our institution, program, and even course have brought international students on and how far the students have come due to the learning impacts. For instance, incorporating value-added assessment in a college ESL program supports evaluating the strengths and weaknesses of the program using different lenses, and it helps determine its impact on students' success. The data gathered could be used both for developmental and judgmental purposes; however, as pointed out earlier, care should be taken in interpreting the data as extraneous variables could have interfering effects on the values added or not added. As an incentive to promote the integration of value-added assessment, colleges or departments may recognize instructors' efforts in different forms, such as recognizing them in performance review forms. However, first, faculty members should own the idea to implement it effectively and efficiently.

\section{Reference}

Bachman, L. (2000). Modern Language Testing at the Turn of the Century: Assuring that What We Count Counts. Language Testing, 17(), pp.1-42.

Bachman, L. and Palmer, A. (2010). Language Assessment in Practice. Oxford: Oxford University Press.

Benjamin, R. (2002). Measuring the Difference in College Makes the RAND/CAE Value-Added Assessment Initiative. [online] Available at: https://www.aacu.org/peerreview/pr-sp02/pr-sp02feature2.cfm on 3/7/2014. Hattie, J. and Timperely, H. (2007). The Power of Feedback. Review of Educational Research, 77(1), pp.81-112. Hughes, A. (2003). Testing for Language Teachers. Cambridge: Cambridge University Press.

Nunley, C., Bers, T. and Manning, T. (2011). National Institute for Learning Outcomes Assessment: Learning Outcomes Assessment on Community Colleges. [online] Available at: http://www.learningoutcomeassessment.org/documents/communitycollege.pdf on 3/7 2014 .

Weir, C.J. (2005). Language Testing and Validation. Basingstoke: Palgrave. 